\title{
An Investigation into Participation Trends by Wheelchair Sports Players at the Zimbabwe Paralympic Games
}

\author{
Bhekuzulu Khumalo $^{1, *}$, Ignatius Onyewandume ${ }^{2}$, John Bae ${ }^{3}$, Shadreck Dube ${ }^{1}$ \\ ${ }^{1}$ National University of Science and Technology (NUST) Zimbabwe \\ ${ }^{2}$ University of Botswana, Botswana \\ ${ }^{3}$ William Paterson University, USA \\ *Corresponding Author: bkhumalo46@gmail.com
}

Copyright (C) 2013 Horizon Research Publishing All rights reserved

\begin{abstract}
Introduction: Disability or the disablement process is manifested in the interaction between the individual and his/her environment. There are general regulations for accessibility inside a building, among such are: Entrance doors, service desk, lifts, stairs, corridors, water closet (WC), and dressing rooms. This research was guided by the United Nations (UN) Accessibility for the Disabled: A Design Manual for a Barrier Free Environment, a document by the UN High Commission for human rights, designed to guide and set standards for built environment accessibility by the disabled. The International Paralympic Committee (IPC) recognises 6 different disability groups: amputees, athletes with Cerebral Palsy (CP), blind or visually impaired athletes, spinal cord injured athletes, athletes with an intellectual/learning disability, other athletes (les autres) with a physical disability who do not fit into the above 5 categories. This research focused on amputees, spinal cord injured athletes and the other athletes with a physical disability e.g. as a result of polio or accidents, who participate in wheel chair basketball and/or tennis. This study aimed at identify problems associated with access to Zimbabwean sport facilities by disabled consumers. The researcher observed that wheelchair sports is failing to attract participants because of challenges faced in accessing sporting facilities, due to: Challenges faced in transport/road usage, to and from sporting facilities. Non adaptation of the sports facilities. Non availability of equipment, e.g. the wheel chairs and rackets. Lack of access to equipment. Methods: Randomly selected wheelchair sports players from Zimbabwe are interviewed and group discussions carried out. Seventy (70) respondents 47 (67.1\%) males and $23(32.9 \%)$ females participated. The majority $(62.9 \%)$ are above 25 years of age, only $22.9 \%$ are 20 years or below, all the females taking part in this research were over 30 years old. Results and Discussion: The results are that the barriers to participation are a result of an unfriendly and non-adapted transport system, poverty, nature of occupation, lack of access to equipment and non-adapted facilities providing health and safety risks over and above accessibility challenges. Conclusion and Recommendations:
\end{abstract}

This research revealed a list of barriers to wheelchair sports participation opening avenues for further research in the areas of mainstreaming and Paralympic sports participation in Zimbabwe.

Keywords Impairment, Disability, Handicap, Adapted, Activity, Physical Activity

\section{Introduction}

The Universal Declaration of Human Rights of 10 December 1948 states: "All human beings are born free and equal in dignity and rights. They are endowed with reason and conscience and should act towards one another in a spirit of brotherhood". Human rights examples include: freedom from discrimination, the right to work, the right to education, the right to participate in sports and recreation, and the right to form a family. Human rights enhance the wellbeing and dignity of an individual and ensure the provision or the protection of basic needs. The denial of human rights signifies that a person's inherent value is not being respected. Persons with a disability face persistent barriers to the enjoyment of basic human rights such as education, employment, access to buildings and transportation and participation in public life. Disability or the disablement process is manifested in the interaction between the individual and his/her environment. The term "disability" is a problematic concept since it refers to, or is associated with, an individualistic and impairment-based understanding. As a term, it is nevertheless applied throughout this text since it is regarded as a commonly accepted concept, and its usage is practical in the absence of any new, easy to use terminology. During the 1970s there was a strong reaction among representatives of organisations of persons with disabilities and professionals in the field of disability against the then current terminology. The new concept of disability is more focused on the close connection between the limitations experienced by individuals with disabilities, the design and structure of their environments and the attitude of the general 
An Investigation into Participation Trends by Wheelchair Sports Players at the Zimbabwe Paralympic Games

population. Recent development has seen a shift in terminology and an increasing tendency towards viewing the disability complex as a process (the disablement process), involving a number of different elements on individual and societal levels. The adoption of the World Health Organisation's (WHO) International Classification of Functioning, Disability and Health (WHO, 2001) represents a milestone in the development of the disability concept. From the introduction of "The International Classification of Impairments, Disabilities and Handicaps (ICIDH)' (WHO, 1980), a 20 year process has resulted in shift in the WHO conceptual framework from a medical model (impairment based) to a new scheme that focuses on limitations in activities and social participation. Although not representing a complete shift from a strictly medical to a strictly social model, the development culminating with ICF nevertheless implies a much wider understanding of disability and the disablement process. The classification forms a basis for the collection of statistical data on disability.

Physical activity and sports for participants with functional limitations and activity restrictions are increasingly being referred to within the framework of Adapted Physical Activity (APA) Sherrill, (2004); Steadward et al., (2003); Winnick, (2005), Health Promotion, Riley et al. (2008), rehabilitation medicine, Roe et al., (2008), , Special Olympics, Shapiro, (2003); Farrell et al., (2004) and Paralympics, Higgs and Vanlandewijck, (2007). The International Paralympic Committee (IPC) recognises six different disability groups: that is amputees, athletes with Cerebral Palsy (CP), blind or visually impaired athletes, spinal cord injured athletes, athletes with an intellectual/learning disability, other athletes (les autres) with a physical disability who do not fit into the above five categories. This research shall focus on amputees, spinal cord injured athletes and the other athletes with a physical disability e.g. as a result of polio or accidents, who participate in wheelchair basketball. Onyewadume, (2007) states that; there is lack of literature, both in international journals and the World Wide Web, on the status and practice of APA in different African countries. The role of the physical and social environment in disabling individuals has been very much in focus during the last 10-20 years leading to the United Nations (UN) adoption of the Standard Rules in 1993, the World Programme of Action (WPA), and lately the International Classification of Functioning (ICF) WHO, (2001). There are general regulations for accessibility inside a building, among such are: Entrance doors, service desks, lifts, stairs, corridors, water closet (WC), and dressing rooms. In Zimbabwe the Disabled Persons Act of 1992, constituted the formation of a disability board. Part of the board's functions is to issue adjustment orders in terms of the act and to formulate and develop measures and policies designed to achieve equal opportunities for people with disabilities by ensuring, so far as possible, that they are able to obtain education and employment, participate fully in sporting, recreation and cultural activities and are afforded full access to community and social services. This research shall be guided by the United Nations (UN) Accessibility for the Disabled: A Design Manual for a Barrier Free Environment, a document by the UN High Commission for human rights, designed to guide and set standards for built environment accessibility by the disabled.

In common with the fate of people with disabilities the world over, people with disabilities in Zimbabwe suffer from widespread violation of their fundamental freedoms and rights. They face exclusion from education, employment, cultural activities, festivals, sports and social events and are especially vulnerable to poverty, physical and sexual violence, lack of access to health care, emotional abuse and neglect. The stigma and discrimination attached to disability stems from the way society views disability: People with disabilities are still being viewed from a medical and welfare framework, identifying people with disabilities as ill, different from their non-disabled peers, and in need of care. As a result of the emphasis on the medical need, there is neglect of the wider political, social and economic needs of people with disabilities and their families. Only 33\% of children with disabilities in Zimbabwe have access to education, compared with over $90 \%$ for the able-bodied population; Central Statistics Office (CSO) 2004. Recognition of disability rights in these areas would lead to improved inclusion in society as well as equal and stronger participation in all facets of life by people with disabilities. According to UN estimates, the population of disabled people in the world is between 225 and 350 million. This is based on a $10 \%$ estimated prevalence rate, WHO (1981), intended to cover severe, moderate and mild disabilities. The large majority of disabled people live in developing or low-income countries, very often living without optimal technical, medical or social support that could improve their level of living conditions considerably. Disabled people are often marginalised and belong to the poorest segments of society, UN (1996).

A UNICEF supported National Disability Survey (MLSS, 1982), was carried out by the Ministry of Labour and Social Welfare, Zimbabwe in 1981. This study revealed that there were approximately a quarter of a million people with disabilities at that time. The most prevalent functional problem was visual impairment $(25 \%$ of all with impairments), followed by impairment in the lower limbs (24\%), upper limbs (12\%), mental retardation or disability problem or emotional illness $(9.7 \%)$, hearing $(8.2 \%)$, speech impairments (7.4\%), and neurological problems $(5.5 \%)$. Diseases, accidents, war-related incidents, and peri-natal factors as malnutrition and hereditary factors were, in descending order, the most commonly stated causes of impairment. The study also comprised a few socio-economic indicators, revealing that $52 \%$ of the persons with disabilities in 1981 had never attended school and that only $1 \%$ had progressed beyond secondary school. Disability was further found to reduce dramatically the individuals' opportunities on the job market. The latest census in Zimbabwe was conducted in 2002; the census questionnaire covered 8 topics which are on the list of recommended core topics based on 
the principles and recommendations for population and housing censuses, revision 2. The topics selected provided information on: geographical and internal migration characteristics, international migration characteristics, household and family characteristics, demographic and social characteristics, fertility and mortality, educational characteristics, economic characteristics and disability characteristics. Preliminary results of the 2002 Census placed the population of Zimbabwe at 11,634,663.
Basing statistical figures on responses to question 14 of the population census, August 2002, questionnaire that reads; "Does (name) have a disability? If yes state type of disability; 0 - Difficulty moving, 1- Difficulty Seeing, 2 - Difficulty Speaking, 3 - Difficulty Hearing, 4 - Difficulty Learning/Mental Handicap, 5- Chronic fits/Epilepsy, 6 Strange Behaviour/Mental Illness, 7 - Lack of Feeling in hands/feet (Leprosy), 8 - Albinism and 9 - Other. Table 1 shows total population by type of disability and province. 
Table 1. Total Population by Type of Disability and Province (Source Census 2002, Profile of Persons with Disability)

\begin{tabular}{|c|c|c|c|c|c|c|c|c|c|c|c|c|}
\hline \multicolumn{13}{|c|}{ Disability } \\
\hline Province & $\begin{array}{c}\text { Difficulty } \\
\text { moving }\end{array}$ & $\begin{array}{l}\text { Difficulty } \\
\text { Seeing }\end{array}$ & $\begin{array}{c}\text { Difficulty } \\
\text { speaking }\end{array}$ & $\begin{array}{c}\text { Difficulty } \\
\text { hearing }\end{array}$ & $\begin{array}{c}\text { Difficulty } \\
\text { learning/Menta } \\
1 \text { handicap }\end{array}$ & $\begin{array}{l}\text { chronic } \\
\text { fits/ } \\
\text { Epilepsy }\end{array}$ & $\begin{array}{c}\text { Strange } \\
\text { Behaviour/ } \\
\text { Mental } \\
\text { Illness }\end{array}$ & $\begin{array}{l}\text { Lack of } \\
\text { Feeling in } \\
\text { hands/feet } \\
\text { (Leprosy) }\end{array}$ & Albinism & $\begin{array}{c}\text { Multiple } \\
\text { Disabilities }\end{array}$ & Other & Total \\
\hline Вуо & 2812 & 2367 & 559 & 664 & 559 & 445 & 803 & 451 & 112 & 597 & 597 & 9927 \\
\hline Man & 11916 & 9961 & 2258 & 3499 & 1915 & 1473 & 4308 & 1670 & 347 & 3331 & 3331 & 44143 \\
\hline Mash C & 8962 & 7166 & 1332 & 2368 & 1045 & 1659 & 2854 & 1561 & 149 & 1893 & 1893 & 30547 \\
\hline Mash E & 11922 & 10961 & 1918 & 3447 & 1863 & 1823 & 3901 & 1403 & 232 & 2716 & 2716 & 43303 \\
\hline Mash W & 10481 & 10236 & 1701 & 3076 & 1301 & 1479 & 3015 & 1235 & 173 & 2842 & 2842 & 37852 \\
\hline Mat N & 7512 & 7383 & 1181 & 3008 & 1267 & 1751 & 2559 & 784 & 115 & 1753 & 1753 & 29618 \\
\hline Mat S & 11023 & 8605 & 1102 & 2557 & 1454 & 1202 & 2627 & 943 & 111 & 2203 & 2203 & 34830 \\
\hline Mid & 13486 & 13160 & 2224 & 3994 & 2020 & 1770 & 3519 & 1778 & 234 & 2842 & 2842 & 47610 \\
\hline Masv & 11856 & 10675 & 1922 & 3091 & 1803 & 1055 & 3250 & 1535 & 251 & 1754 & 1754 & 39446 \\
\hline Hre & 8893 & 8215 & 1854 & 2294 & 1488 & 1358 & 2439 & 1080 & 375 & 1968 & 1968 & 31585 \\
\hline Total & 98863 & 88729 & 16051 & 27998 & 14715 & 14025 & 29275 & 12440 & 2099 & 21899 & 22767 & 348861 \\
\hline
\end{tabular}

Table 2. Percentage Distributions by Population by Province and Sex. (Source Census 2002, Profile of Persons with Disability)

\begin{tabular}{|c|c|c|c|c|c|c|}
\hline Province & Males & Females & Percent & Total Number & Percent & Sex Ratio \\
\hline Bulawayo & 51.98 & 48.02 & 100.00 & 9927 & 2.85 & 108.25 \\
\hline Manicaland & 49.78 & 50.22 & 100.00 & 44143 & 12.65 & 99.12 \\
\hline Mashonaland Central & 51.76 & 48.24 & 100.00 & 30547 & 8.76 & 107.30 \\
\hline Mashonaland East & 49.92 & 50.08 & 100.00 & 43303 & 12.41 & 99.68 \\
\hline Mashonaland West & 51.80 & 48.20 & 100.00 & 37852 & 10.85 & 107.47 \\
\hline Matabeleland North & 50.77 & 49.23 & 100.00 & 29618 & 8.49 & 103.13 \\
\hline Matabeleland South & 46.41 & 53.59 & 100.00 & 34830 & 9.98 & 86.60 \\
\hline Midlands & 50.21 & 49.79 & 100.00 & 47610 & 13.65 & 100.84 \\
\hline Masvingo & 48.88 & 51.12 & 100.00 & 39446 & 11.31 & 95.62 \\
\hline Harare & 54.80 & 45.20 & 100.00 & 31585 & 9.05 & 121.24 \\
\hline Total & 50,41 & 49.59 & 100.00 & 348861 & 100.00 & 101.65 \\
\hline
\end{tabular}


The results show that the total population of persons with disability was mostly rural with only $19 \%$ of the total found in urban areas. The population of persons with difficulty in moving (mobility disabilities) is given as 98863 which is about $28 \%$ of the disabled persons population in Zimbabwe. It is said that $69 \%$ of the persons with disability fall within the age group $15-64$ years. Persons of African ethnic origin made up almost the entire population while those of non-African ethnic origin accounted for a negligible 0.74 percent. The census information on education revealed that about $16 \%$ of the population age $3-24$ years had never been to school. This is a worrying revelation in a country where $98 \%$ of the population is literate.

Adapted Physical Activity (APA) refers to movement, physical activity and sports in which special emphasis are placed on the interests and capabilities of individuals with limiting conditions, such as the disabled, health impaired or elderly. APA professionals' goals are to empower all individuals to participate in regular physical activity throughout their lives. "We value and promote physical activity as a means of recreation, sport, therapy, fitness or expression." IFAPA By-Laws [adopted by the Board of Directors in May 1997 in Quebec City (Canada)] acknowledge that: The particular focus of IFAPA programmes and activities are on individuals with impairments, conditions, disabilities or handicaps that may limit the individuals' ability to pursue the physical activities of interest to them. Disciplines relevant to APA are: (a) biomechanics (b) sport psychology (c) exercise physiology (d) sociology and (e) motor behaviour. Applying paradigms and methodologies of these disciplines within APA contexts are helpful in designing and providing services and practices to individuals with limited function. The Adaptation theory is strongly related to empowerment, ecological task analysis and service delivery. Environmental factors suggested by ICF may produce inaccessible barriers or facilitators to participation, based on the degree of provision of the following:

- Products and technology enabling accessibility.

- Natural environment and human-made changes to the environment.

- Support and relationships of parents, and significant others.

- Attitudes of coach, teacher, peers and significant others.

- Services, systems and policies, including transportation.

Dispositional person factors that are not related to a specific health condition, including gender, somatotype and psychological attributes such as sense of coherence and goal perspective, may influence the degree of participation and the activity outcome related to a specific context. A contextual analysis of personal and environmental factors and appropriate measures could decrease unwanted outcomes. Sherrill, C, and DePauwk, K. (1997) looked at APA as, "The art and science of managing variables so as to achieve desired outcomes" any physical activity can be modified or adapted. Physical activity should be carried out in accordance with the specific considerations of the disability, and may include changes in:

- Equipment: e.g. the use of different materials and different sized balls

- Environment: e.g. lowering the height of the net; decreasing the size of the court.

- Task: making activities easier, altering the goal, e.g. playing volleyball while seated or in wheelchair.

- Rules: e.g. allowing the tennis ball to bounce twice before it is returned (extending the time available for hitting the ball.) - Instruction: Adjusting to cognitive abilities, e.g. keeping it short and simple, giving one instruction at a time, moving in a straight line rather than in a circle.

These adaptations can be organised by activity and health condition. There is need to consider issues such as: Assessment of current state of functioning, suggesting concrete goals and identifying adaptations required to fulfil goal. The environment imposes constraints that afford the individual to develop patterns that would accomplish the task. Individuals adapt to and alter the environment each time they respond to it. Therefore, patterns need not always be stable, but rather changing, based on the action development and the relationships between individual and environment. A charter was adopted in Europe, specifically called for governments and local public authorities to make legal provisions for individuals with disabilities, as well as for the national governing bodies of education, sport and recreation to increase the rules and regulations permitting access and participation of individuals with disabilities. Suggested provisions included: (a) accessible sports facilities (b) transport assistance and (c) technical aids to allow participation in physical activity among others. Countries like Zimbabwe, in the process of introducing and promoting Paralympic sports, need to take a leaf out of such initiatives and act towards mass participation at all levels and by all members of our society. Education, concerning disabilities and moving towards inclusion, is important at both the learning phase and the teaching phase of physical activity and sport. The main goal of PE in school should be to provide a basis for an active life style, by introducing: basic motor activity patterns, introductory group games, established ball games, aquatics and fitness.

Environmental factors are important elements in the ICF model, and it is fundamental to the present understanding of disability that activity limitations and restrictions in participation are formulated in the exchange between an individual and his/her environment. The concepts of "level of living" or "living conditions" have developed from a relatively narrow economic and material definition to a current concern with human capabilities and how individuals utilise their capabilities, Heiberg \& Øvensen, (1993). Although economic and material indicators play an important role in the tradition of level of living an individual's level of living is usually defined not so much by his or her economic possessions, but by the ability to exercise choice and to affect the course of his or her own life. The level of living studies have been more and more concerned with examining the degree to which people can participate in social, political and economic decision-making and can work creatively and productively to shape their own future (UNDP, 1997). Disability is thus present if an 
individual is (severely) restricted in his/her daily life activities due to a mismatch between functional abilities and demands of society. It is logical that this development is followed by research on the mechanisms that produce disability in the interaction between the individual and his/her environment. The main aim of recreational activities is to facilitate an active lifestyle and free choice of how to organise one's leisure time. Therefore, provision of recreation opportunities for individuals with disabilities is closely related to accessibility issues and awareness activities in the social environment. Recreation is becoming more integrated and inclusive due to people's increased awareness and also legislation. Some countries, Zimbabwe included, do however lag behind others in meeting rights to equal opportunities and each country varies in its provision of sports and recreation activities. Competitive sports for individuals with disability are governed by several international organisations that have evolved in the last century. Those with mobility problems participate mainly in wheelchair sports under the wheel chair and amputee sports association (WASA) and wheelchair basketball is specifically governed by the international wheelchair basketball federation (IWBF) rules.

This research aimed at the following focus areas: Problem identification: defines problems encountered by the disabled in the transport usage and built-up environment owing to the absence or improper application of a certain measure or provision. Existing constructions: defines the problems encountered in existing constructions which hinder participation. Accordingly, alternative solutions and modifications shall be suggested.

\section{Definition of Terms}

Impairment - the existence or occurrence of an anomaly, defect, loss in a limb, organ, tissue or other structure of the body, including the system of mental function.

Disability - any restriction or lack of ability to perform an activity within the range considered normal for a human being.

Handicap - a disadvantage for a given individual, resulting from an impairment or disability that limits or prevents the fulfilment of a normal role.

Adapted-modified.

Activity - movement.

Physical Activity - the art and expertise of managing personal and environmental factors, where special emphasis is placed on the interests and capabilities of individuals with limiting conditions, such as the disabled, health impaired or elderly.

\section{Statement of Purpose}

There is an observed general trend in the annual Zimbabwe Paralympic games that most provincial wheelchair sports teams are not bringing in new players, a scenario that is a threat to the development and growth of
Paralympic sports in the country. This study seeks to identify problems associated with access to Zimbabwean sport facilities and possible needs for adaptation of these facilities to better accommodate disabled consumers. This researcher believes that if the physical barriers are resolved people with physical disabilities, who are otherwise discouraged from taking part in sporting events, may be more likely to participate as spectators, coaches, officials, administrators etc. leading to greater and quality participation in Paralympic sports. Research-based information has been very useful for advocacy purposes, for education and attitude change in the population, as well as for planning and resource allocation purposes. How this is understood and carried out has major impact on the results of research, and consequently on the application of results.

\section{Hypothesis}

Wheelchair sports are failing to attract participants due to challenges faced in accessing sporting facilities, due to:

a) Challenges faced in transport/road usage to and from sporting facilities.

b) Non adaptation of the sports facilities.

c) Non availability of the equipment, e.g. the wheel chairs.

d) Lack of access to equipment.

\section{Objectives}

1. To investigate challenges faced by wheelchair users in the use of public transport and roads in Zimbabwe.

2. To investigate participation trends in wheelchair sports by physically disabled persons in Zimbabwe.

3. To investigate the reasons for participation or non-participation, in wheelchair sports by Zimbabwean disabled players.

4. To open avenues for further research in area of Paralympic sports in Zimbabwe.

\section{Study Population and Sample}

In the Profile of Persons with a Disability of December 2004, the Central Statistics Office (CSO) gives the population of persons with mobility disabilities as 98,863 which is about $28 \%$ of the population of disabled persons in Zimbabwe. This study focused on physically disabled persons that participate or potentially would participate in wheelchair sports. Random sampling, was used, where the researchers visited playing venues and competitions interviewed participants that arrived before training/competition in order of their arrival, players awaiting their turn. The total sample size interviewed in the study is seventy (70), members at wheelchair sports teams around Zimbabwe. The sample includes 47 (67.1\%) males and $23(32.9 \%)$ females. The majority (62.9\%) are above 25 years of age, only $22.9 \%$ are 20 years or below, all the females taking part in this research were over 30 years old. 


\section{Methodology}

A pre-experimental study design based on collecting, presenting, analysing, and interpreting data by observing what people do and say, was carried out. Information was captured through interviews, and group discussions. Morton, (1968) says there are basically two styles of research: theory testing and theory building. Theory building begins with observations and uses inductive reasoning to derive a theory from these observations, on the other hand theory testing approach begins with a theory and uses theory to guide which observations to make, it moves from the general to the particular. This research is basically towards theory building. Theories allow us to select out from a mass of confusing materials those elements of reality which are of concern to us. Theories are based on the fact that social phenomena can be quantified, measured and expressed numerically or otherwise. The researcher randomly interviewed selected facility users and used group discussions at the end of training/competition to clarify, validate and/or consolidate information given during the interviews. To select the interviewees the researcher arrived at each of the training venues before scheduled training/competition time and interviewed the players and officials as they arrived making an effort not to disturb training/competition time. At the end of training the researcher would be granted some time for group discussion with the players. Wheelchair sports players in Zimbabwe participated in this research. The researcher designed an interview schedule/questionnaire. This instrument collects bio data and focuses on, individual income, participation in the national Paralympic games, distances from training venues, and satisfaction with transport utilization to and from the facility, facility entrance, restroom utilization, and access to adapted equipment. To identify these items, the survey questionnaire consists of three main sections. The first section shall collect general demographic information and the second section inquires about consumer satisfaction with sport facility utilization using a 5 -point Likert-type scale $(1=$ Strongly Disagree; $2=$ Disagree, $3=$ Neutral; $4=$ Agree; $5=$ Strongly Agree), the items examine how likely the consumer would be satisfied to use the facility. The third section requires a list (team card) of the players each respondent played with at each of the four Paralympic games i.e. Bulawayo (2008), Masvingo (2009), Mutare (2010) and Chonhoyi (2011).

\section{Reliability and Validity}

Golasfshani (2003) says the difference in purposes of evaluating the quality of studies in quantitative and qualitative research is one of the reasons that the concept of reliability is irrelevant in qualitative research. Unlike quantitative researchers who seek causal determination, prediction, and generalization of findings, qualitative researchers seek instead illumination, understanding, and extrapolation to similar situations, Hoepfl, (1997). While the terms reliability and validity are essential criterion for quality in quantitative paradigms, in qualitative paradigms the terms credibility, neutrality or conformability, consistency or dependability and applicability or transferability are to be the essential criteria for quality, Lincoln \& Guba (1985). 'Dependability', in qualitative research will closely correspond to the notion of 'reliability' in quantitative research. 'Inquiry audit' is cited as one measure which might enhance the dependability of qualitative research, Lincoln \& Guba (1985). Hoepfl (1997) says this can be used to examine both the process and the product of the research for consistency, and to ensure reliability in qualitative research, examination of trustworthiness is crucial. Seale 1999 in Golasfshani (2003), says the "trustworthiness of a research report lies at the heart of issues conventionally discussed as validity and reliability'.

\section{Issues of Access and Ethical Research Practice}

Participation in this research was by informed consent and all participants were given the freedom to choose to participate and withdraw at any stage of the research.

\section{Results}

In this survey, members of wheelchair sports clubs/teams in, Zimbabwe participated. It is important to point out that over $65 \%$ of the male players do not rely on wheelchairs for activities of daily living. These were randomly selected and interviewed in line with the schedule. Seventy (70) individuals were interviewed, $47(67.1 \%)$ were males and $23(32.9 \%)$ were females. The majority $(62.9 \%)$ are above 25 years of age, all the females taking part in this research were over 30 years old. Only $22.9 \%$ are 20 years or below, effectively these are males. See table 3.

In this survey $52.9 \%$ of the respondents are self-employed, $12.9 \%$ work in the private sector , $7.1 \%$ are civil servants (work for government departments), $4.3 \%$ run own businesses and $15.7 \%$ are students. See figure 1 . The results also reflect that most of the respondents are low income earners, with $73.6 \%$ earning less than 200 US dollars per month, further inquiry revealed that most of them rely on street vending as a source of income. Regarding participation in the four editions of the Paralympic games, i.e. Bulawayo (2008), Masvingo (2009), Mutare (2010) and Chinhoyi (2011), 67.6\% participated in all four editions, $10.0 \%$ in three, $14.2 \%$ in two and only $8.2 \%$ participated in one of the editions. The majority $(48.3 \%)$ of the interviewees reside $6-10 \mathrm{~km}$ away from the sporting facilities, $40.2 \%$ are $0-5 \mathrm{~km}$ away and $11.5 \%$ are more that $15 \mathrm{~km}$ away. The result confirm that this is a low income population, where $73.6 \%$ are earning less than US\$200.00 (see figure 2). This will have a negative impact on participation since wheelchair sports is an equipment based sports, one has to purchase/access and maintain the wheelchair, rackets, gloves etc. 
Table 3. Age distribution

\begin{tabular}{|c|c|c|c|c|c|}
\hline & & Frequency & Percent & Valid Percent & Cumulative Percent \\
\hline \multirow{7}{*}{ Valid } & $5-10$ yrs & 1 & 1.4 & 1.4 & 1.4 \\
\hline & $11-15 \mathrm{yrs}$ & 2 & 2.9 & 2.9 & 4.3 \\
\hline & $16-20 \mathrm{yrs}$ & 13 & 18.6 & 18.6 & 22.9 \\
\hline & $21-25 \mathrm{yrs}$ & 10 & 14.3 & 14.3 & 37.1 \\
\hline & $26-30 \mathrm{yrs}$ & 7 & 10.0 & 10.0 & 47.1 \\
\hline & 30 or more yrs & 37 & 52.9 & 52.9 & 100.0 \\
\hline & Total & 70 & 100.0 & 100.0 & \\
\hline
\end{tabular}

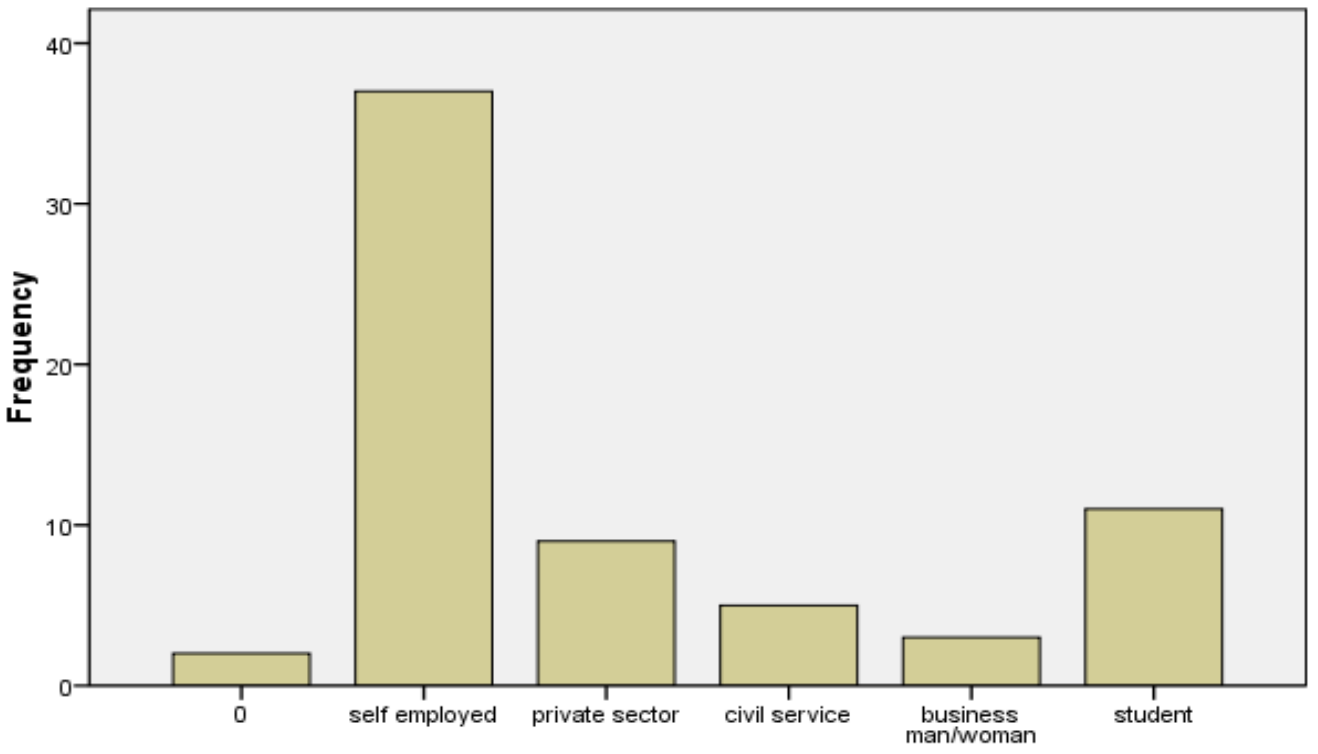

Figure 1. Occupation of the respondents.

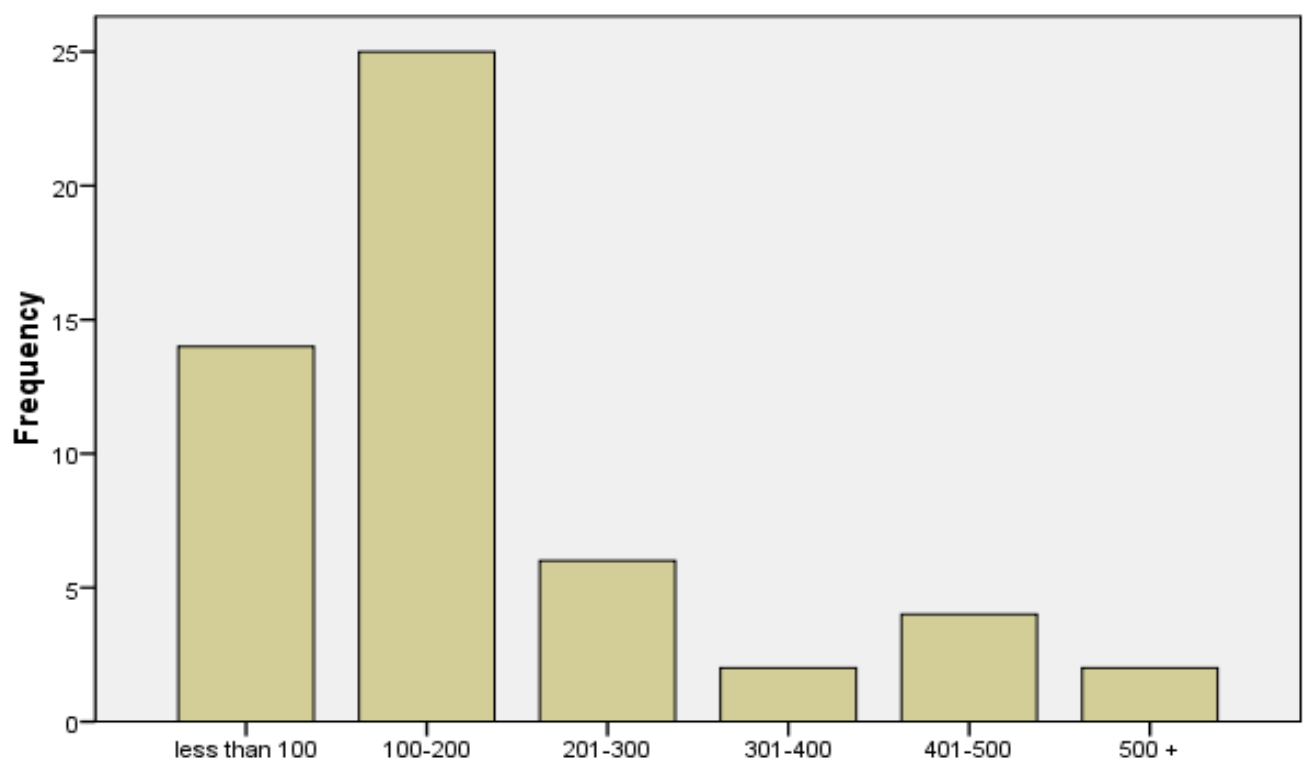

Figure2. Income levels of the respondents. 
The respondents generally $(72.7 \%)$ disagree that it is convenient and safe for them to use public transport and $75.0 \%$ are dissatisfied with its usage. The incline of surface to get on and off public transport is said to be inconvenient by $76.5 \%$ of the respondents, with $5.9 \%$ taking a neutral view over the issue. Discussions revealed that most if not all public transport vehicles in Zimbabwe are not adapted for use by wheelchair users. The players are not satisfied with transport as $75.0 \%$ of the respondents disagree with only $14.3 \%$ agreeing with the statement: "I am satisfied with public transportation station because it is located in/or near sports facility." Some $17.6 \%$ did not have problems with the incline as they did not find it inconvenient to use, these are participants who do not use wheel chairs for daily activity and mobility, as they can move independently, or with some prosthesis or orthotics. The interviewees largely $(88.2 \%)$ do have access to adapted equipment, for public transport usage or sports participation, as $94.1 \%$ do not have access to own wheel chair for playing sports. High quality of surface of public transportation station is convenient for me to access, $67.7 \%$ of the respondents do not agree with this statement. $61.3 \%$ of the respondents do not agree with the statement, "Incline of surface is convenient for me to get on and off from the public transportation." While only $22.6 \%$ do agree with it and only $1.6 \%$ strongly agree, "It is easy for me to find an accessible entrance". There is no clear alignment on this issue of convenience in using and having enough space when I go in and out in the restroom. as $47.6 \%$ disagrees, $31.8 \%$ agrees and $20.6 \%$ have a neutral opinion. The responses on the statement were so much dependent on the facility used hence the distribution of $43.5 \%$ on the disagreeing side, $34.3 \%$ agree and $17.7 \%$ were neutral. The responses the statement, "I am satisfied with door opening mechanisms in the restroom," were $54.1 \%$ disagree, and $31.2 \%$ agree, with $14.8 \%$ neutrals. $50.8 \%$ of the respondent indicated no problems in using the sink in a toilet, with $31.1 \%$ disagreeing with the statement, it is convenient for me to use a sink. $45.8 \%$ said the environment in the restroom is clean, with $33.2 \%$ disagreeing and $22.0 \%$ taking a neutral stance. A good $37.9 \%$ reported inconveniences in the use of door stalls, $54.3 \%$ reported no inconveniences, these being the ones who least rely on prosthesis, orthotics or wheel chairs for mobility.

The participants reported that their team composition had hardly changed from the one edition of the Paralympic games to the other; this was evident from the last question (8) where they are asked to list team members for each of the four editions of the previous Paralympic games.

\section{Discussion}

It is of concern that most of the participants in wheelchair sports are well over the age of 26 years and there is negligible injection of new blood in the sports a situation that is worrying if one considers the future of the sport. The low income levels of the respondents is a factor likely to militate against sports participation, one of the interviewees actually pointed out that she had no source of income and relied of a friend for transport fares to and from training and these both leave about $5 \mathrm{~km}$ from the training venue. During the interviews the respondents did point out that distance from the facility contributes to irregular attendance or eventually lead to no attendance to training sessions by some of their club members, leading to a loss of participants. Due to the low income the players face challenges in the acquisition of adapted equipment for their sport participation. The clubs/teams are actually struggling through training sessions and to maintain player membership as players are sharing the wheelchairs during training sessions, meaning the chairs are not adapted to specific players. For those who make it to training the lack of equipment means long hours at the facility where most of the time is spent doing nothing (idle). As most of these people survive on one form or the other of self-employment they end up relating this idle time to lost income (revenue), they say they could have used it to make some money from an income generating activity.

While issues of access convenience and hygiene at the venues did affect some participants especially those who are not wheelchair users the spirit was that they are more likely to be rectified in the not so distance future. These barriers, the participants felt, can in short to medium term be addressed through own efforts in collaboration with the responsible authorities, hence the spirit is let's move on as we work towards rectification. This is the spirit today, but one can see that in not so far a future these barriers are going to impact negatively on Paralympic sports participation. With more discussions the interviewees were in agreement that some people have stayed away from the sports due to the challenges presented by these physical barriers. Distances from the training facilities also work against participation, due to low non availability of fares, as a result of low incomes, non-adapted transport system, attitudes of transport crews especially to wheel chair users. None of the vehicles used as public transport are adapted for use by wheelchair users, the crews usually view waiting for disabled person to manoeuvre his/her way into and out of the vehicle as time wasting in a highly competitive industry.

These militating factors have led to difficulties in retaining and worse still recruiting new and younger players, hence one sees the same people representing the province time and again.

\section{Recommendations}

As an immediate solution one will recommend taking the sport to the people. Bulawayo residential areas have many basketball courts in schools, youth clubs and halls that can be used for the indoor game. Outdoor courts at schools, colleges and youth clubs generally need no adaptation for use by wheelchair basketball teams. The main challenge would come with the use of rest and change rooms as these did not take any consideration of the disabled during their construction. As medium to long term there need be a rigorous campaign towards adaptation of facilities and the acquisition of adapted equipment for use at training and during the games. In-depth research at national level looking at attitudes, challenges and inspecting the facilities in line with internationally set adaptation standards needs to be carried out. 


\section{Appendix}

\section{Paralympic Games Participation Survey Interview Schedule}

This schedule intends to find out the participation trend in wheel chair basketball in the 2008 (Bulawayo), 2009 (Masvingo) 2010 (Mutare) and 2011 (Chinhoyi) Paralympic Games. For each of the following statements, please the box that best answers the question.

1. What is your gender? 1 . Male $\square 2$ Female $\square$

2. What is your age? 5-10 yrs $\square$ 11-15 yrs $\square 16-20$ yrs $\square$ 21-25yrs $\square$ 26-30 yrs $\square 30$ or more

3. Which of the games did you participate in? Bulawayo $\square$ Masvingo $\square$ Mutare $\square$ Chinhoyi

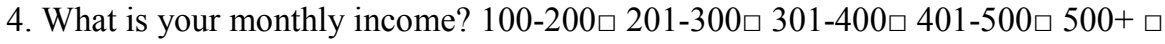

5. I participated in the games as a: Player/Athlete $\square$ Coach $\square$ Official/Referee $\square$

6. What is the estimated distance from nearest sporting facility? $1-5 \mathrm{~km} \square 6-10 \mathrm{~km} \square 11-15 \mathrm{~km} \square$ More than $\square$

7. For each of the following statements, please circle the numbers that indicate the degree of satisfaction on your using a sport facility. "1=Strongly Disagree (SD) 2= Disagree (D) 3=Neutral (N) 4=Agree (A) 5=Strongly Agree (SA)"

\begin{tabular}{|c|c|c|c|c|c|}
\hline & SD & D & $\mathbf{N}$ & $\mathbf{A}$ & SA \\
\hline 1. It is convenient and safe for me to use public transportation & 1 & 2 & 3 & 4 & 5 \\
\hline 2. It is convenient and safe for me to use public transportation & 1 & 2 & 3 & 4 & 5 \\
\hline 3. I am satisfied with public transportation & 1 & 2 & 3 & 4 & 5 \\
\hline $\begin{array}{l}\text { 4. Incline of surface is convenient for me to get on and off from the public } \\
\text { transportation }\end{array}$ & 1 & 2 & 3 & 4 & 5 \\
\hline 5. Access to adapted equipment & 1 & 2 & 3 & 4 & 5 \\
\hline 6. Availability of wheel chairs & 1 & 2 & 3 & 4 & 5 \\
\hline 7. I am satisfied with door opening mechanisms in the restroom. & 1 & 2 & 3 & 4 & 5 \\
\hline 8. It is convenient for me to use a toilet. & 1 & 2 & 3 & 4 & 5 \\
\hline 9. It is convenient for me to use a sink & 1 & 2 & 3 & 4 & 5 \\
\hline 10. Environment in the restroom is clean. & 1 & 2 & 3 & 4 & 5 \\
\hline 11. It is inconvenient for me to use door on stall. & 1 & 2 & 3 & 4 & 5 \\
\hline 12.It is convenient for me to use a toilet. & 1 & 2 & 3 & 4 & 5 \\
\hline 13.It is convenient for me to use a sink. & 1 & 2 & 3 & 4 & 5 \\
\hline 14.Environment in the restroom is clean. & 1 & 2 & 3 & 4 & 5 \\
\hline 15.It is inconvenient for me to use door on stall & 1 & 2 & 3 & 4 & 5 \\
\hline
\end{tabular}

16. Kindly list the members of your team by completing the following table.

\begin{tabular}{|c|c|c|c|c|c|c|c|}
\hline \multirow[b]{2}{*}{ Name and Surname } & \multirow{2}{*}{$\begin{array}{c}\text { Male/ } \\
\text { Female }\end{array}$} & \multirow[b]{2}{*}{ Age } & \multirow[b]{2}{*}{ Province } & \multicolumn{4}{|c|}{ Games at which he/she participated } \\
\hline & & & & Bulawayo & Masvingo & Mutare & Chinhoyi \\
\hline & & & & & & & \\
\hline & & & & & & & \\
\hline & & & & & & & \\
\hline & & & & & & & \\
\hline & & & & & & & \\
\hline & & & & & & & \\
\hline & & & & & & & \\
\hline & & & & & & & \\
\hline & & & & & & & \\
\hline & & & & & & & \\
\hline & & & & & & & \\
\hline & & & & & & & \\
\hline & & & & & & & \\
\hline
\end{tabular}

Thank you very much for your cooperation. 


\section{REFERENCES}

[1] Farrell RJ, Crocker PRE, McDonough MH, Sedgwick WA. 2004. The driving force: Motivation in Special Olympians. Adapted Physical Activity Quarterly 21(2):153-166.

[2] Higgs C, Vanlandewijck Y. (2007). Perspectives Volume 7: Sports for Persons with a Disability. Berlin: International Council of Sport Science and Physical Education (ICSSPE).

[3] Riley BB, Rimmer JH, Wang E, Schiller WJ. (2008). A conceptual framework for improving the accessibility of fitness and recreation facilities for people with disabilities. Journal of Physical Activity \& Health Jan 5(1):158-168.

[4] Roe C, Dalen H, Lein M, Bautz-Holter E. (2008). Comprehensive rehabilitation at Beitostølen Healthsports Centre: influence on mental and physical functioning. Journal of Rehabilitation Medicine Jun 40(6):410-417.

[5] Shapiro DR. (2003). Participation motives of Special Olympics athletes. Adapted Physical Activity Quarterly 20(2):150-166.

[6] Sherrill, C. (2004). Adapted physical activity, recreation and sport: Crossdisciplinary and lifespan (6th ed.). Boston, MA: McGraw-Hill Higher Education.

[7] Steadward, R. D., Wheeler, G.D., \& Watkinson, E. J. (Eds.). (2003). Adapted physical activity. Edmonton, Canada: The University of Alberta Press.

[8] Winnick JP, (Ed). (2005). Adapted physical education and sport. 4th ed. Champaign (IL): Human Kinetics.

[9] World Health Organisation (2001). International classification of functioning, disability and health (ICF). Geneva, Switzerland: Author [On-line]. Available: http://www3.who.int/icf/icftemplate.cfm. 12-01-11]

[10] Behling, Orlando and Kenneth S. Law (2000). Translating questionnaires and other research instruments: Problems and solutions. Thousand Oaks, CA: Sage Publications. Series: Quantitative Applications in the Social Sciences No. 133.

[11] Bouchard C, Shephard RJ, Stephens T (1994) Physical activity, fitness, and health: International proceedings and consensus statement. Champaign, IL: Human Kinetics Publishers.

[12] Bourque, Linda B. and Eve P. Fielder (2002a). How to conduct self-administered and mail surveys, Vol. 3. Thousand Oaks, CA: Sage Publications.

[13] Central Statistics Office, Zimbabwe (2004) Profile of Persons of with a Disability Accordio et al (2006)

[14] Converse, Jean M. and Stanley Presser (1986). Survey questions: Handcrafting the standardized questionnaire. Thousand Oaks, CA: Sage Publications. Quantitative Applications in the Social Sciences Series No. 63.

[15] Disabled Persons Act (1992)

[16] Dufon, M. A. (2002) Video recording in ethnographic research: Some issues of validity in data collection, Language, Learning \& Technology, (6), available
http://www.questia.com/googleScholar.qst;jsessionid=HW4 YrpVdvXCXB2yXldjpp8v2G11xl

[17] Farrell RJ, Crocker PRE, McDonough MH, Sedgwick WA. (2004). The driving force: Motivation in Special Olympians. Adapted Physical Activity Quarterly 21(2):153-166.

[18] Golafshani, N., (2003) Understanding reliability and validity in qualitative research; The qualitative report, 8(4), available: http://www.nova.edu/ssss/QR/QR8-4/golafshani.pdf [accessed 08 March 2010]

[19] Higgs C, Vanlandewijck Y. (2007). Perspectives Volume 7: Sports for Persons with a Disability. Berlin: International Council of Sport Science and Physical Education (ICSSPE).

[20] Hoepfl, M. C. (1997). Choosing qualitative research: A primer for technology education researchers, Journal of Technology Education, 9(1), 47-63, available: http://scholar.lib.vt.edu/ejournals/JTE/v9n1/pdf/hoepfl.pdf [accessed 17 February 2010]

[21] Lincoln, Y. S., and Guba, E. G. (1985), Naturalistic inquiry, SAGE Publications,

[22] Onyewadume I.U. (2007) Adapted physical activity in Africa; Problems and the way forward: Sabona Journal, December 2007, Vol. 12, n.I. Supplement pp 58-63

[23] Riley BB, Rimmer JH, Wang E, Schiller WJ. (2008). A conceptual framework for improving the accessibility of fitness and recreation facilities for people with disabilities. Journal of Physical Activity \& Health Jan 5(1):158-168.

[24] Roe C, Dalen H, Lein M, Bautz-Holter E. (2008). Comprehensive rehabilitation at Beitostølen Healthsports Centre: influence on mental and physical functioning. Journal of Rehabilitation Medicine Jun 40(6):410-417.

[25] Sackett, D. L. and Wennberg, J. E. (1997) Choosing the best research design for each question, Hanover, New Hampshire, available:

http://www.bmj.com/cgi/content/full/315/7123/1636 [accessed 05 December 2010]

[26] Seidel, J. V. (1998) Qualitative data analysis; available: $\mathrm{ftp}: / / \mathrm{ftp}$.qualisresearch.com/pub/qda.pdf [accessed 25 January 2010]

[27] Shapiro DR. (2003). Participation motives of Special Olympics athletes. Adapted Physical Activity Quarterly 20(2):150-166.

[28] Sherrill, C. (2004). Adapted physical activity, recreation and sport: Crossdisciplinary and lifespan (6th ed.). Boston, MA: McGraw-Hill Higher Education.

[29] Steadward, R. D., Wheeler, G.D., \& Watkinson, E. J. (Eds.). (2003). Adapted physical activity. Edmonton, Canada: The University of Alberta Press.

[30] Strauss, A., and Corbin, J. (1990) Basics of qualitative research: Grounded theory procedures and techniques, Sage Publications, Inc, Newbury Park.

[31] Sungwon Bae, Kyoungtae Kim, E. Newton Jackson, and Ki-Yong Park, (2004)

[32] The Nuremberg Code (1947) Permissible medical experiments; British Medical Journal, 7070(313)1448, available: http://www.cirp.org/library/ethics/nuremberg/ 
[accessed 15thJanuary 2008]

[33] Thomas, J. R., Nelson J. K., Silverman S. (2005) Research Methods in physical activity, 5thed, Human Kinetics, Leeds.

[34] Winnick JP, (Ed). (2005). Adapted physical education and sport. 4th ed. Champaign (IL): Human Kinetics.

[35] Wiseman, Jacqueline P. (1970) Field projects for sociology students: Schenkman Pub. Co; distributed by Canfield Press, San Francisco.

[36] World Health Organisation (2001). International classification of functioning, disability and health (ICF). Geneva, Switzerland: Author [On-line]. Available: http://www3.who.int/icf/icftemplate.cfm. [Accessed 12-01-11] 